\title{
Noise Levels in a Medical Intensive Care Unit
}

\author{
Jinyi $\mathrm{He}^{1}$, Hong $\mathrm{Li}^{2}$, Xiaohuan $\mathrm{Chen}^{2}$, Shuang $\mathrm{Jin}^{2}$, Meirong $\mathrm{Chen}^{2}$, Lan $\mathrm{Shi}^{3}$, Fenghua $\mathrm{Su}^{4}$ \\ 1.The Fourth Department of Critical Care Medicine,2.Nursing Department,3.The Second Department of Critical \\ Care Medicine,4.Department of Nursing, Fujian Provincial Hospital, Fuzhou 350001, China
}

\begin{abstract}
This study was undertaken to investigate and analyze noise pollution in a large Chinese governmental hospital' s medical intensive care unit and compare to the WHO guidelines. This cross-sectional study was conducted in a MICU at a public governmental teaching hospital in Fujian province between July and August of 2017. A WENSN® WS1361 Integrated Sound Level Meter (China) was used for continuous every five seconds one week noise levels recording. After this measurement, the decibel meter was used for recording different location of isolation rooms and open bays, including occupied and unoccupied patient, and recording sound events occurs in the ICU to identify sources of noise. Peak and average noise levels were obtained from the meter, and data were downloaded from the WS1361 into a laptop computer. The measured mean equivalent sound pressure levels (L) and standard Aeq deviation over one week period were 66.64 $\pm 7.57 \mathrm{~dB}(\mathrm{~A})$, with acute spikes reaching $119.7 \mathrm{~dB}(\mathrm{~A})$, the average sound level for a 24 hour period in a work day was $68.03 \pm 5.07 \mathrm{~dB}(\mathrm{~A})$. These are higher than the current daytime environmental noise limit of 40-45 decibels in China and WHO. Mean work day noise was significantly louder than weekend time, there was a significant difference in work days and weekend $(\mathrm{t}=16.85 ; \mathrm{P}=0.000)$. There was a statistical difference between the day time and night time shifts $(\mathrm{t}=34.67 ; \mathrm{P}=0.000)$. The isolation rooms were significantly quieter than the open-bay rooms $(t=46.15 ; p=0.00)$, sound levels in the occupied and unoccupied rooms also had significant difference $(\mathrm{t}=17.26 ; \mathrm{P}=0.000)$. Two types of noise resources, including twenty kinds sources were identified and measured, mean noise levels ranged from of 61.33 to $79.21 \mathrm{~dB}(\mathrm{~A})$. This study shows noise levels in intensive care units were exceeded the recommended. The study of the influence of noise on patient and staff is needed, and noise reduction strategies must be conduct in ICU.
\end{abstract}

Keywords: Noise; Noise Levels; Noise Measurement; Medical Intensive Care Units; Nursing 


\section{Introduction}

In the past half century, the develop of science and technology have afforded medical countless new equipment and machines that have allowed patients to undergo medical procedures with improved outcomes[1,2]. However, these beneficial advances are were accompanied by the corresponding noises that result from their use[3,4]. In addition, poor design of hospital acoustic environment also contributes to increased noise[5,6].

Noise, defined as unwanted sounds, could affect people both psychologically and physiologically[7].Noise also has been defined as an accidental sound wave without any rhythm or harmony which can interfere with hearing[8]. To quantify sound levels, the decibel, an arithmetically non-dimensional linear scale, defines measured sound pressure[9,10], in which sound is measured as the force per unit area that sound waves produce. For sound pressure measurement that closely resembles the normal curve for loudness frequency of the human ear, the internationally agreed 'A' weighted filter is used[11].

A hospital intensive care unit (ICU) is designed to treat critically ill patients who need special care and treatment, sometimes at nearly the same extreme level required in an operating room $[12,13]$. ICUs contain many sources of noise, such as aspirators, monitors, mechanical ventilators, computers, printers, air conditioning vents, and others[14]. The adverse effects of elevated noise in hospitals have been documented in many researches, high noise levels interfere with communication, leads to attention loss, irritability, fatigue, headache, muscle contractures, increased heart rate and blood pressure, in addition to worsened quality of sleep both in the healthcare professionals' team and patients[15-19].

The improvement of technology has increased noise levels in Intensive Care Units, many hospitals fail to meet the limits of noise guidelines recommend by the World Health Organization. The assessment of noise and the impact of noise pollution have been extensively studied in the developed countries, but there were not many studies about this in China.

Noise generated in ICUs has increased in recent decades due to a substantial increase in the number of devices with acoustic alarms, and background noise by actions and speaking of healthcare professionals[14,20,21]. Many researches show that noise levels measured in ICU are far exceeding the recommended standards for hospitals and generally measured around 
60-70 dB (A), with peaks rising up to $80-120 \mathrm{~dB}(\mathrm{~A})[2,20-27]$. The World Health Organization has drawn up guidelines for community noise management, the recommended noise levels in hospital should be $35-40 \mathrm{~dB}(\mathrm{~A})$ in the daytime and $30-40 \mathrm{~dB}(\mathrm{~A})$ in the evening $[1,20,28,29]$. According to the Emission Standard for Community Noise of China, the background noise limit for a medical institution is $40-45 \mathrm{~dB}$ at daytime and $30-35 \mathrm{~dB}$ at nighttime.

Due to the importance of noise pollution level in the ICU, the purpose of this study was to measure noise level in an MICU, compare the results to recommended levels, identify some sources of noise and to develop effective noise reduction strategies in the future.

\section{Materials and Methods}

\subsection{Ethical}

The hospital ethics committee approved the study. The patients and MICU staff were informed about this study, no individuals were recruited for participation in the study and patient care was not affected during the collection of data.

\subsection{Study Design and Setting}

This was a cross-sectional study. It is a quantitative, descriptive and exploratory study using data collected in a MICU at a public governmental teaching hospital in Fujian province between July and August of 2017. The hospital is located on the crossroads of main road in the heart of Fuzhou municipal (province capital, 7,115,370 inhabitants), MICU is on the hospital's sixth floor and has a rectangular shape, including 15 open-bay rooms and 5 isolate rooms, five of the rooms are contact isolation rooms with 3 walls and a automatic door, whereas the other patient care bays are open bays with 2 walls and a curtain.

\subsection{Instrument}

The equipment used in this study included a portable computer equipped with the Sound Level Meter software (provided with the device) and a sound level meter with a tripod.

The variable noise was measured using a WENSN ® WS1361 Integrated Sound Level Meter (WENSN, Shenzhen, Guangdong) with scale A and scale C, and fast and slow two channels, the readings are in Decibel, A-weighted (dBA) units representing the sound level measured with the A-weighting network on the sound level meter. Officers from the Aural Displays and Bioacoustics Branch were consulted regarding the reliability and validity of the 
WS1361. the WS1361 provided a direct reading of sound over the ranges of 30-130 dB(A), with accuracy of $\pm 0.5 \mathrm{~dB}(\mathrm{~A})$ at 25 degree centigrade. with an accuracy of less than $\pm 1 \mathrm{~dB}(\mathrm{~A})$ over temperature ranges $0-50 \mathrm{C}$.

Scales $\mathrm{A}$ and $\mathrm{C}$ under fast mode were used to register the data because that speed makes it possible to measure kinds of noise that do not oscillate rapidly. Scale A (dBA), is the filtering method that simulates the receptive characteristics of the human ear and it is recommended to capture continuous noise, mostly used for measuring environmental noise. A common method used in the discussion of noise pollution is the equivalent continuous noise level (Leq) expressed in $\mathrm{dB}(\mathrm{A})$, the other variables obtained were percentile level LN, such as the L10and L90, the maximum and minimum noise levels recorded at the same measurement period

\subsection{Data Collection}

The data were collected during 2015, according to the Emission standard for community noise (China, 2008), the WS1361 equipment was placed at approximately a distance of $1 \mathrm{~m}$ from the sound sources or $0.5 \mathrm{~m}$ from reflector, set up on a tripod and $1.2 \mathrm{~m}$ from the floor. Utilizing this distance from the floor, the equipment was placed in the middle of the nursing station and patient room and so on. The device was calibrated according to the manufacturer's instructions for standardization purposes before starting each measuring task.

Measurements were made in 4 phases, the noise level measurements did not, at any time, interfere with the work of the staff. A major concern during the data-collection procedure was to ensure that no bias existed while the measurements were being taken.

Phase 1 Implement pilot measurement to confirm the reliability and validity of the data collected. With prior authorization from the hospital and department management, first day was explained the purples of the research and where the measuring was taking place to the staff including physician, nurse and other person in MICU. After that, the WS1361 equipment with a tripod was continually placed in the middle of the nursing station started to pilot measurement. Because of the direct measurement of noise levels within a clinical environment meant there was the potential for staff influence the noise levels primarily through the 'Hawthorn effect' inasmuch that individuals who are aware of their participation in a study change their behavior accordingly[28,30-32]. Pilot measurement would help to 
reduce the possible influence hospital staff may have had on the noise levels being recorded in their respective areas[14]. This phase constants one week, the data was discarded.

After one week pilot measurement, the staffs were familiar with the equipment and researchers to continue with their routine activity. In phase 2, the ambient noise in the MICU was measured. The sound levels meter placed at the same position of phase 1, without the knowledge of the staffs when the measuring was started, the researcher who collected data was in there sporadically as before. This phase constants one week, from Monday to Sunday, the day shift (8:00 a.m. to 8:00 p.m.), versus night shift (8:00 p.m. to 8:00 a.m.) and work days (Monday to Friday) versus weekend days (Saturday and Sunday) were considered in the analysis.

Phase 3 was to make measurement in both occupied and unoccupied patient rooms in different location of the unit.

In phase 4 , measurements of different events or routine activities to identify sources of noise in MICU were taken. Any specific events that were thought to contribute to excessive noise were also to be measurement and documented.

Phase 3 and phase 4 were took place in day time ( 8 a.m. to 12 a.m. and 2 p.m. to 6 p.m.) which recommend by the Emission standard for community noise (China, 2008). During the measurement, at 24 hours intervals the device was connected to a computer with the Sound Level Meter software that stored and read the data specifics. When the collection was complete, the data were transferred to SPSS, for analysis.

\subsection{Statistical Analysis}

Descriptive results were given in frequencies and percentages. Continuous variables were compared using the Student $t$ test. If more than 2 variables were compared, a 1-way analysis of variance (ANOVA) was used. Statistical significance was defined as a P value $<0.05$. Data are shown as mean \pm SEM. All data analysis was performed using the Statistical Package for the Social Sciences for Windows 19.0 (SPSS Inc., Chicago, IL, USA).

\section{Result}

During the study, the beds occupation rate in the MICU was $98 \%$, similar to the same period of last two years $99 \%$ and $97 \%$, staffs present as usual and without any construction change. 
The measured mean equivalent sound pressure levels (L) and standard Aeq deviation over one week period were $66.64 \pm 7.57 \mathrm{~dB}(\mathrm{~A})$, with acute spikes reaching $119.7 \mathrm{~dB}(\mathrm{~A})$, Mean work day noise was significantly louder than weekend time, there was a difference in work days and weekend(Table 1).

Table 1- Noise levels recorded by week time in MICU

\begin{tabular}{cccccc}
\hline Variables & LAeq & Minimum & Maximum & L10 & L90 \\
\hline Hold week & $66.64(7.57)$ & $60.98(3.91)$ & $84.58(9.27)$ & $72.97(5.30)$ & $63.44(2.54)$ \\
Work days & $67.13(3.30)$ & $61.87(3.75)$ & $88.62(8.49)$ & $75.67(4.33)$ & $64.32(2.43)$ \\
Weekend & $63.39(7.94)$ & $59.19(3.78)$ & $78.41(7.72)$ & $67.58(1.58)$ & $61.67(1.78)$ \\
t & 16.85 & 2.62 & 3.68 & 8.75 & 3.50 \\
P & 0.000 & 0.028 & 0.005 & 0.000 & 0.007 \\
\hline
\end{tabular}

Result express as mean(standard deviation)

The average overall sound level for a 24 hour period obtained in a work day during the continuous weekly measurement was $68.03 \pm 5.07 \mathrm{~dB}(\mathrm{~A})$. When comparisons were made between nursing shifts (day and night), mean noise levels reported ( $\mathrm{t}=34.67 ; \mathrm{P}=0.000$ ) were found to be statistically significant differences(Table 2).

Table 2- Noise levels recorded by nursing shift in MICU

\begin{tabular}{cccccc}
\hline Variables & LAeq & Minimum & Maximum & L10 & L90 \\
\hline Hold day & $68.03(5.07)$ & $61.99(2.35)$ & $81.96(9.11)$ & $72.96(5.51)$ & $66.23(3.55)$ \\
Day & $70.25(4.91)$ & $62.59(2.52)$ & $88.66(4.02)$ & $76.74(3.28)$ & $67.83(3.19)$ \\
Night & $65.80(4.16)$ & $61.39(2.04)$ & $75.60(8.45)$ & $69.19(4.63)$ & $64.62(3.20)$ \\
t & 34.67 & 2.55 & 7.60 & 6.98 & 4.17 \\
P & 0.000 & 0.018 & 0.000 & 0.000 & 0.000 \\
\hline
\end{tabular}

Result express as mean(standard deviation)

Noise levels were variety in different location of the department, dataset recorded in bedside showed that room near nursing station had higher mean noise levels than those far from it, the distribution of the noise levels measured in different location are given on Table 3. Mean noise levels in isolation rooms was significantly different $(t=46.15 ; p=0.00)$ with the open-bay layout rooms(Table 4), the results also showed that the sound levels in the occupied and unoccupied rooms had significant difference $(\mathrm{t}=17.26 ; \mathrm{P}=0.000)$.

To determine the dominant noise sources, the magnitude and frequency of noise sources were obtained, two types of noise resources were identified and measured, equipment and its 
alarm and human vocalization (Table 5).

Table 3- Noise levels in different locations of MICU

\begin{tabular}{lccccc}
\hline Locations & Mean & SD & Minimum & Maximum & Confidence limit (99\%) \\
\hline Bed 1 & 67.30 & 4.70 & 59.1 & 83.7 & $66.44-68.16$ \\
Bed 2 & 64.01 & 3.56 & 58 & 82.9 & $63.35-64.66$ \\
Bed 3 & 63.03 & 4.13 & 56.1 & 89.1 & $62.27-63.79$ \\
Bed 4 & 69.25 & 4.89 & 60.5 & 87.3 & $68.35-70.15$ \\
Bed 5 & 66.73 & 3.52 & 60.9 & 91.1 & $66.09-67.38$ \\
Bed 6 & 67.11 & 3.54 & 60.7 & 79.6 & $66.46-67.77$ \\
Bed 7 & 66.24 & 6.26 & 59.2 & 90.9 & $65.09-67.39$ \\
Bed 8 & 64.74 & 3.70 & 58.8 & 76.2 & $64.06-65.42$ \\
Bed 9 & 65.94 & 3.82 & 60.1 & 87.6 & $65.23-66.64$ \\
Bed 10 & 66.19 & 5.57 & 58.4 & 92.1 & $65.17-67.22$ \\
Bed 11 & 61.31 & 3.46 & 56.5 & 86.9 & $60.67-61.94$ \\
Bed 12 & 66.23 & 5.01 & 58.3 & 90.2 & $65.30-67.15$ \\
Bed 13 & 64.51 & 3.52 & 58.6 & 89.6 & $63.86-65.15$ \\
Bed 14 & 66.19 & 3.90 & 59.7 & 82.9 & $65.48-66.91$ \\
Bed 15 & 69.36 & 3.87 & 62.5 & 87.8 & $68.65-70.07$ \\
Bed 16 & 58.76 & 2.14 & 55.2 & 66.3 & $58.34-59.16$ \\
Bed 17 & 63.49 & 2.68 & 58 & 78.8 & $63.00-63.99$ \\
Bed 18 & 57.69 & 3.64 & 51.8 & 66.4 & $57.01-58.35$ \\
Bed 19 & 58.07 & 6.74 & 51.7 & 97.8 & $56.65-59.49$ \\
Bed 20 & 56.33 & 2.96 & 53.2 & 77.1 & $55.78-56.87$ \\
\hline & & & & & \\
\hline
\end{tabular}

Table 4 Noise levels recorded by room type and occupation

\begin{tabular}{lrcc}
\hline \multicolumn{1}{l}{ Locations } & $\mathrm{t}$ & $\mathrm{P}$ \\
\hline Room type (Unoccupied) & & \\
Open bay & $63.94(3.29)$ & 46.15 & 0.000 \\
Isolated & $51.83(2.00)$ & & \\
Occupation (Isolated room) & & \\
Unoccupied & $51.83(2.00)$ & & \\
Occupied & $56.33(2.96)$ & & \\
\hline
\end{tabular}

Table 5- Noise sources and levels recorded in the MICU

\begin{tabular}{lcc}
\hline Events & Mean & $\begin{array}{l}\text { Standard } \\
\text { Deviation }\end{array}$ \\
\hline $\begin{array}{l}\text { Mechanical noise } \\
\text { Cardiac monitor }\end{array}$ & 74.26 & 6.68 \\
\hline
\end{tabular}




\begin{tabular}{lll}
\hline Ventilator & 70.20 & 3.06 \\
Vacuum extractor & 72.12 & 5.73 \\
Infusion pump & 71.34 & 4.20 \\
Atomization device & 64.54 & 6.05 \\
Oxygen & 64.58 & 3.99 \\
Medical cart & 73.04 & 9.76 \\
Radiology & 73.61 & 8.14 \\
Printer & 72.57 & 7.13 \\
Telephone ring & 74.12 & 6.15 \\
Human vocalization & & \\
Nursing intervention & 70.64 & 8.13 \\
Medical treatment & 71.41 & 4.69 \\
Replacing beds & 73.42 & 5.18 \\
Patient admitting & 74.02 & 7.09 \\
Centralize visiting & 73.20 & 4.43 \\
Conversation & 75.51 & 6.99 \\
Bedside endorsement & 79.21 & 5.49 \\
Conference & 61.33 & 6.28 \\
Footsteps & 64.76 & 3.43 \\
Cleaning or sweeping & 74.35 & 5.09 \\
\hline
\end{tabular}

\section{Discussion}

The results of our study showed that the constant measurement of mean sound level during a week and a work day were $66.64 \mathrm{~dB}(\mathrm{~A})$ and $68.03 \mathrm{~dB}(\mathrm{~A})$, respectively, with maximum level reach $119.7 \mathrm{~dB}(\mathrm{~A})$. Consistent with and correlate well with previous studies in ICU throughout the different countries with average sound level measurements between 60 to $80 \mathrm{~dB}$ and peaks reaching over $110 \mathrm{~dB}[2,18,20-22,24-27,29,32,33]$. Those results were far beyond the standards recommended by WHO and the Emission Standard for Community Noise of China for hospitals and ICU. However, a recent literature review reported that no study found that the noise level in the ICU was within the recommended levels by the WHO and/or the EPA[14,19,20,26].

The distribution of mean noise levels measured for 24 hours in a work day vary systematically over the day, and the data recorded evidenced a higher level in the day shift. This finding similar to the results of some studies in which sound levels in the ICU were lower at night than during the day[2,8-10,12,14,20,24,26,33-35]. The mean noise levels measured at each location differ statistically, the wards located close to nurses' station were suffer higher mean noise levels than those away from it(Table 3). Though the ICU is as an 
emergency unit, our study found mean noise levels was significant different in work day and weekend, work days were shown to be more noisy, this was perhaps there were different work routines and different number of staff present between work day and weekend.

It can be seen from the results that the level of noise in different locations of department and the mean minimum noise level during one week measurement period did not drop below $50 \mathrm{~dB}(\mathrm{~A})$, this can be explained by the very nature of the environment, the ambient environment of the MICU is filled with high noise levels. Noise in a public hospital is unavoidable but at the same time, long-term noise exposure is regarded as a health hazard[36], and numerous previous studies had showed that high noise level has deleterious physical and psychological effects on both patient and staff, such as hypertension, altered heart rates and muscle tone, headaches, hearing loss, mental confusion, low attention span and irritability[4,15-19,25,31,34,37-42].

According to Emission standard for industrial enterprise noise at boundary (China,2008), 8 hours of continuous exposure to a noise level of $85 \mathrm{~dB}$ is permissible daily. Although the mean noise levels during constant measurement period no values above $85 \mathrm{~dB}$ in this study, the mean maximum noise level was close to it, and the work day had exceeded it (88.62 \pm 8.49$)$. Typically, the maximum noise level events did not continuously over an 8-hour per day, most were intermittently about 30 seconds. This value may indicate the risk of developing negative effects solely from the exposure. However, the longer noise exposure, the higher risk obtained, and patients and healthcare staff may be affected alike. Ways and means of reducing the levels of noise in preclinical should be taken into consideration because these noise levels have a potential to cause damage over a prolonged exposure.

Previous literature show that, since the 1960s, the average noise levels inside hospitals have increased by an average of $0.38 \mathrm{dBA}$ (day) and $0.42 \mathrm{dBA}$ (night) per year[43]. As noise in a workplace may originate from several sources, noise levels increased in ICUs maybe due to a substantial increase in the number of devices with acoustic alarms, and background noise by actions and speaking of healthcare professionals[14].

In our study, as there were many active noise sources at the same time and sound events were not isolated, we were not able to appreciate the entire noise sources, two types of noise resources, mechanical noise and human vocalization, including twenty kinds' sources that 
familiar in ICU were identified, and most of those noise sources' mean levels are higher than average level of the day (Table 5), thus, those noise sources may the main events related to increased noise levels in ICU.

The exact source of excessive noise pollution within the ICU is multi-factorial, some researchers suggested that the majority of noise created in their ICU was created by mechanical alarms[25,32], while other discovered that medical and more so nursing staff were just as responsible for noise production in the ICU[11,24,44]. Obviously, it difficult to attributing blames which source is responsible.

Our study found there was significant different between occupied wards and unoccupied wards which without equipment operated, and there was statistically significant differences in work day and less staff present's weekend, It makes clear that both mechanical noise and human vocalization contribute to make our MICU a noisy environment. Furthermore, the potentially poor acoustical design in the ICU may be integrated together to increased noise levels.

As noted by Konkani and Oakley[12] reduction of sound levels in hospital ICUs to the recommended level of $45 \mathrm{~dB}(\mathrm{~A})$ is clearly an important goal, there is a great deal of work remains to be done to make significant progress in this area. A calm and pleasant healing environment may benefit both patients and health care staff alike[3,5,27,29,37,42,45,46].

There were a few limitations to our study. Although there was a pilot measurement to confirm the reliability and validity of the data collected, the potential for the Hawthorne effect still cannot be ruled out. Without implement long-term constantly measurements, the nursing staff may have been more cautious about their behaviour and intentionally decreased the noise level. Because there were so many noise sources at a time in MICU, it was difficult to identify the noise sources separately and measure noise levels in different location at the same time. We did not measure the spectral content of the sound, neither. In addition, we made no measurements of the perception in both health care staff and patient, and the influence of noise on them.

\section{Conclusion}

The findings of this study validate those of other studies conducted in MICU, it showed that MICU is indeed a noisy environment, the excessive sound levels that do not meet Chinese or WHO's standards and recommendations for hospital and ICU. The MICU noise levels were found to be high especially during day time and work days. The distribution of noise levels in different locations and different room style were differed significantly, and there is still need to elucidate the exact sources of noise. In conclusion, this study makes it clear that action strategies should be taken to reduce noise levels in ICU. 


\section{Acknowledgement}

The authors thank the Fujian Province Health and Family Planning Commission's Youth Research Foundation (2014-1-8) for the support.

Conflicts of Interest: The authors have no conflict of interest to declare. 


\section{References}

1. Basner, M.; McGuire, S. Who environmental noise guidelines for the european region: A systematic review on environmental noise and effects on sleep. Int J Environ Res Public Health 2018, 15.

2. White, B.L.; Zomorodi, M. Perceived and actual noise levels in critical care units. Intensive Crit Care Nurs 2017, 38, 18-23.

3. Cunha, M.; Silva, N. Hospital noise and patients' wellbeing. Procedia - Social and Behavioral Sciences 2015, 171, 246-251.

4. Brown, B.; Rutherford, P.; Crawford, P. The role of noise in clinical environments with particular reference to mental health care: A narrative review. Int J Nurs Stud 2015, 52, 1514-1524.

5. Bartley, J.; Streifel, A.J. Design of the environment of care for safety of patients and personnel: Does form follow function or vice versa in the intensive care unit? Crit Care Med 2010, 38, S388-398.

6. Bartley, J.M.; Olmsted, R.N.; Haas, J. Current views of health care design and construction: Practical implications for safer, cleaner environments. Am J Infect Control 2010, 38, S1-12.

7. $\quad$ Kang, J. Urban sound environment. CRC Press: 2006.

8. Khademi, G.; Roudi, M.; Farhat, A.S.; Shahabian, M. Noise pollution in intensive care units and emergency wards. Iranian journal of otorhinolaryngology 2011, 23, 141.

9. Bentley, S.; Murphy, F.; Dudley, H. Perceived noise in surgical wards and an intensive care area: An objective analysis. Br Med J 1977, 2, 1503-1506.

10. Seidlitz, P. Excessive noise levels detrimental to patients, staff. Hospital progress 1981, 62, 54-56, 64.

11. Kam, P.; Kam, A.; Thompson, J. Noise pollution in the anaesthetic and intensive care environment. Anaesthesia 1994, 49, 982-986.

12. Konkani, A.; Oakley, B. Noise in hospital intensive care units - a critical review of a critical topic. Journal of critical care 2012, 27, 522. e521-522. e529.

13. Medicine, S.o.C.C. Guidelines for intensive care unit design guidelines. Practice Parameters Committee of American College of Critical Care Medicine: 1995.

14. Christensen, M. Noise levels in a general surgical ward: A descriptive study. Journal of clinical nursing 2005, 14, 156-164.

15. Bosma, K.J.; Ranieri, V.M. Filtering out the noise: Evaluating the impact of noise and sound reduction strategies on sleep quality for icu patients. Crit Care 2009, 13, 151.

16. Meyer, T.J.; Eveloff, S.E.; Bauer, M.S.; Schwartz, W.A.; Hill, N.S.; Millman, R.P. Adverse environmental conditions in the respiratory and medical icu settings. CHEST Journal 1994, 105, 1211-1216.

17. Morrison, W.E.; Haas, E.C.; Shaffner, D.H.; Garrett, E.S.; Fackler, J.C. Noise, stress, and annoyance in a pediatric intensive care unit. Critical care medicine 2003, 31, 113-119.

18. Stanchina, M.L.; Abu-Hijleh, M.; Chaudhry, B.K.; Carlisle, C.C.; Millman, R.P. The influence of white noise on sleep in subjects exposed to icu noise. Sleep medicine 2005, 6, 423-428.

19. Xie, H.; Kang, J.; Mills, G.H. Clinical review: The impact of noise on patients' sleep and the effectiveness of noise reduction strategies in intensive care units. Critical Care 2009, 13, 208.

20. Tainter, C.R.; Levine, A.R.; Quraishi, S.A.; Butterly, A.D.; Stahl, D.L.; Eikermann, M.; Kaafarani, H.M.; Lee, J. Noise levels in surgical icus are consistently above recommended 
standards. Crit Care Med 2016, 44, 147-152.

21. Kramer, B.; Joshi, P.; Heard, C. Noise pollution levels in the pediatric intensive care unit. $J$ Crit Care 2016, 36, 111-115.

22. Munro, N. Sleep deprivation in critically ill patients. Advance for Nurses 2002, 3, 13-16.

23. Lawson, N.; Thompson, K.; Saunders, G.; Saiz, J.; Richardson, J.; Brown, D.; Ince, N.; Caldwell, M.; Pope, D. Sound intensity and noise evaluation in a critical care unit. American Journal of Critical Care 2010, 19, e88-e98.

24. Hilton, B. Noise in acute patient care areas. Research in nursing \& health 1985, 8, 283-291.

25. Falk, S.A.; Woods, N.F. Hospital noise-levels and potential health hazards. New England Journal of Medicine 1973, 289, 774-781.

26. Tegnestedt, C.; Gunther, A.; Reichard, A.; Bjurstrom, R.; Alvarsson, J.; Martling, C.R.; Sackey, P. Levels and sources of sound in the intensive care unit - an observational study of three room types. Acta Anaesthesiol Scand 2013, 57, 1041-1050.

27. Johansson, L.; Knutsson, S.; Bergbom, I.; Lindahl, B. Noise in the icu patient room - staff knowledge and clinical improvements. Intensive Crit Care Nurs 2016, 35, 1-9.

28. Seaman, C.H. Research methods: Principles, practice, and theory for nursing. Appleton \& Lange: 1987.

29. Konkani, A.; Oakley, B. Noise in hospital intensive care units--a critical review of a critical topic. J Crit Care 2012, 27, 522 e521-529.

30. Polit, D.F.; Beck, C.T. Nursing research: Principles and methods. Lippincott Williams \& Wilkins: 2004.

31. Polgar, S.; Thomas, S.A. Introduction to research in the health sciences. Elsevier Health Sciences: 2013.

32. Balogh, D.; Kittinger, E.; Benzer, A.; Hackl, J. Noise in the icu. Intensive care medicine 1993, 19, 343-346.

33. Tsiou, C.; Eftymiatos, D.; Theodossopoulou, E.; Notis, P.; Kiriakou, K. Noise sources and levels in the evgenidion hospital intensive care unit. Intensive care medicine 1998, 24, 845-847.

34. Sampaio Neto, R.d.A.; Mesquita, F.O.d.S.; Junior, P.; Siqueira, M.D.; Ramos, F.F.; Andrade, F.M.D.d.; Junior, C.; de Valois, M.A. Noise in the intensive care unit: Quantification and perception by healthcare professionals. Revista Brasileira de terapia intensiva 2010, 22, 369-374.

35. Darbyshire, J.L.; Young, J.D. An investigation of sound levels on intensive care units with reference to the who guidelines. Critical Care 2013, 17, R187.

36. Ising, H.; Kruppa, B. Health effects caused by noise: Evidence in the literature from the past 25 years. Noise and Health 2004, 6, 5 .

37. Bazuin, D.; Cardon, K. Creating healing intensive care unit environments: Physical and psychological considerations in designing critical care areas. Critical Care Nursing Quarterly 2011, 34, 259-267.

38. Bion, V.; Lowe, A.S.; Puthucheary, Z.; Montgomery, H. Reducing sound and light exposure to improve sleep on the adult intensive care unit: An inclusive narrative review. I Intensive Care Soc 2018, 19, 138-146.

39. Blomkvist, V.; Eriksen, C.A.; Theorell, T.; Ulrich, R.; Rasmanis, G. Acoustics and psychosocial environment in intensive coronary care. Occup Environ Med 2005, 62, e1. 
40. Locihova, H.; Axmann, K.; Padysakova, H.; Fejfar, J. Effect of the use of earplugs and eye mask on the quality of sleep in intensive care patients: A systematic review. J Sleep Res $\mathbf{2 0 1 8}$, 27, e12607.

41. Ma, K.W.; Wong, H.M.; Mak, C.M. A systematic review of human perceptual dimensions of sound: Meta-analysis of semantic differential method applications to indoor and outdoor sounds. Building and Environment 2018, 133, 123-150.

42. Persson Waye, K.; Elmenhorst, E.M.; Croy, I.; Pedersen, E. Improvement of intensive care unit sound environment and analyses of consequences on sleep: An experimental study. Sleep Med 2013, 14, 1334-1340.

43. Busch-Vishniac, I.J.; West, J.E.; Barnhill, C.; Hunter, T.; Orellana, D.; Chivukula, R. Noise levels in johns hopkins hospital. The Journal of the Acoustical Society of America 2005, 118, 3629-3645.

44. Cmiel, C.A.; Karr, D.M.; Gasser, D.M.; Oliphant, L.M.; Neveau, A.J. Noise control: A nursing team's approach to sleep promotion: Respecting the silence creates a healthier environment for your patients. AJN The American Journal of Nursing 2004, 104, 40-48.

45. Nimlyat, P.S.; Kandar, M.Z. Appraisal of indoor environmental quality (ieq) in healthcare facilities: A literature review. Sustainable Cities and Society 2015, 17, 61-68.

46. Abbas, M.Y.; Ghazali, R. Physical environment: The major determinant towards the creation of a healing environment? Procedia - Social and Behavioral Sciences 2011, 30, 1951-1958. 